\title{
A Survey on Smart Grid Potential Applications and Communication Requirements
}

\author{
V. Cagri Gungor, Member, IEEE, Dilan Sahin, Taskin Kocak, Salih Ergut, Concettina Buccella, Senior \\ Member, IEEE, Carlo Cecati, Fellow, IEEE, and Gerhard P. Hancke, Senior Member, IEEE
}

\begin{abstract}
Information and communication technologies (ICT) represent a fundamental element in the growth and performance of smart grids. A sophisticated, reliable and fast communication infrastructure is, in fact, necessary for the connection among the huge amount of distributed elements, such as generators, substa-tions, energy storage systems and users, enabling a real time ex-change of data and information necessary for the management of the system and for ensuring improvements in terms of efficiency, reliability, flexibility and investment return for all those involved in a smart grid: producers, operators and customers. This paper overviews the issues related to the smart grid architecture from the perspective of potential applications and the communications requirements needed for ensuring performance, flexible operation, reliability and economics.
\end{abstract}

Index Terms-Advanced Metering Infrastructure (AMI), demand Response, smart Grid Communications.

\section{Introduction}

Global warming, an increase in carbon emissions, and the growing world population and power demand have provoked governments and energy utilities to take solid steps towards the use of renewable energies, their integration within the existing power transmission and distribution systems and the increase of the efficiency and flexibility of the latter [41].

The existing grid was developed using a centric approach: relatively few very high-power ac plants (hundreds of MVA) operating at 50 or $60 \mathrm{~Hz}$ interconnected by ac or dc transmission systems operating at very high voltages (e.g., $400 \mathrm{kV}$ ), many substations, where the high voltage is reduced to distribution level (e.g., $20 \mathrm{kV}$ ), a huge number of distribution lines sup-

V. C. Gungor, D. Sahin, and T. Kocak are with the Department of Computer Engineering, Bahcesehir University, Besiktas, Istanbul, 34353, Turkey (e-mail: cagri.gungor@bahcesehir.edu.tr; dilan.sahin@stu.bahcesehir.edu.tr; dilansahin@gmail.com; taskin.kocak@bahcesehir.edu.tr).

S. Ergut is with AVEA, Ýstanbul, Turkey. (e-mail: salih.Ergut@avea.com.tr).

C. Buccella and C. Cecati are with the Department of Industrial and Information Engineering and Economics, University of L'Aquila, and with DigiPower Ltd. L'Aquila, Italy (e-mail:concettina.buccella@univaq.it; carlo.cecati@univaq.it).

G. P. Hancke is with the Department of Electrical, Electronic and Computer Engineering, University of Pretoria, Pretoria, South Africa (e-mail:g.hancke@ieee.org; Gerhard.Hancke@up.ac.za). plying the loads directly (in the case of high-power loads) or after voltage reduction (e.g., $400 \mathrm{~V}$ in Europe), such as in residential or low-power industrial loads.

Recently, renewable energy generators, which produce a few kilowatts in the case of residential photovoltaic systems, up to some megawatts in the case of large photovoltaic and wind generators, are becoming widely diffused around the world, thus transforming the present power system in a large-scale distributed generation system (DG) incorporating thousands of generators, characterized by different technologies, voltage, current, and power levels, as well as topologies [24], [33]. Hence, their integration with the existing network is transforming the whole electrical power system [24], [45]. However, there are many issues on the ground and they are complicated by the aging infrastructure of the existing power grid, which already cause problems to utilities and customers, being unreliable, with low power quality, hence too high and increasing cost and low customer satisfaction.

The power grid infrastructure is very critical and contains a large number of interconnected components: generators, power transformers, and distribution feeders that are geographically spread. Moreover, its increasing complexity, the huge number of geographically spread generators, and the side effects caused by the variable nature and high penetration of renewable energy systems (RES) make it very vulnerable, thus requiring sophisticated security mechanisms [28].

The current power network was designed as a centralized system such that the electric power flows unidirectional through transmission and distribution lines from power plants to the customer premises. The intelligence is concentrated in central locations and only partially in substations, while remote terminations (i.e., loads) are almost or totally passive. The new systems would provide higher and widely distributed intelligence embedded in local electricity production, two-way electricity and information flows, thus achieving reliable, flexible, efficient, economic, and secure power delivery and use [22].

The new approach, widely known as Smart Grid (SG), requires both a complex two-way communication infrastructure, sustaining power flows between intelligent components, and sophisticated computing and information technologies, as well as business applications. They enable, among others, new approaches in grid management by applying demand side management and providing grid energy storage, needed for load balancing and for overcoming energy fluctuations caused by the intrinsic nature of RES, preventing widespread power grid cascading failures [6], and enabling the integration of plug-in hy- 


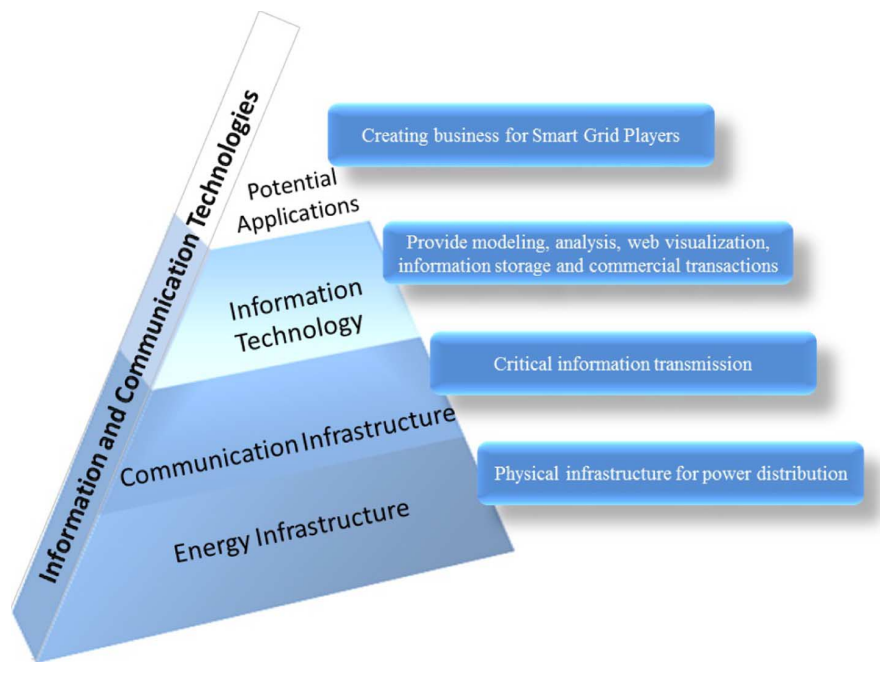

Fig. 1. SG framework integrating energy infrastructure with the communica-tion, computing and information technologies, and business applications.

brid and electric vehicles (PHEV and PEV), thus reducing emissions from the transportation industry, providing storage and matching the generation and load balance [23], [34], [45].

Fig. 1 summarizes the main issues related to $\mathrm{SG}$ (from bottom to top): the energy infrastructure represents the physical infrastructure for energy generation, transmission, and distribution; the communication infrastructure is responsible for transferring the critical information through the network; Information Technology provides modeling, analysis, web visualization, and commercial transactions; potential applications are responsible for distinguishing the use cases of infrastructure usage. The communication infrastructure performs a critical role in the overall smart grid framework. Connecting all relevant components in the grid is very important to collect information about the conditions of the components for control, monitoring, and maintenance purposes. Any problems related to the energy infrastructure can be avoided if proper action is taken immediately with the help of the communication infrastructure. Different communication technologies can be used for different purposes and requirements of each specific application. Information technology provides a common platform for sharing the information coming from different business fields related to the smart grid by giving support to the collection of different information, analysis, and advanced applications and providing the integration of information from different layers of the smart grid. Potential applications propose better management, automation, detection, and generation techniques for the overall system; fundamental applications generally focus on reducing the electricity consumption in homes, offices, and factories and changing the customer consumption behaviors with advances in-home displays and energy dashboards, etc.

In Fig. 2, instead, the components of all of the smart grid layers are illustrated from the energy infrastructure to the potential applications.

This paper is organized as follows. Section II, after a definition of the smart grid from the power system point of view, briefly describes the smart grid communication architecture and its main elements. Section III introduces and analyzes some key applications and their main communication requirements. Section IV reviews an SG applications and services roadmap. Finally, Section V presents conclusions.

\section{SG Communication Architecture}

\section{A. General Overview}

The SG concept aims to achieve a sophisticated system by integrating an information and communication technology infrastructure to the existing power system infrastructure and the new distributed generation system, in order to fully exploit the use of renewable energy systems and to maximize energy efficiency of the whole power system. From a slightly different perspective, a "smart grid" can be considered as a data communication network that achieves, with the support of specific power management hardware devices, flexible, seamless inter-operation abilities among different advanced components of the system for efficient utilization of the energy [12].

SG end-to-end architectures basically comprise of three main layers: the SG application layer, the power layer, and the communication layer.

1) Application Layer: It includes advanced applications providing inter-operability among them. Demand response management, outage management, advanced metering infrastructure, asset management, and fraud detection are among the most considered. A detailed view of applications is included in Section III.

2) Power Layer: The fundamental novelty in SG comes with: 1) the integration of renewable energy sources that disrupt the balance of the prediction of energy sources and the replacement of the one-way communication system and 2) two-way communication between the customer and the utility that will enable the possibility to balance between demand and supply of the energy. Therefore, the power generation, transmission and distribution system, and customer premises are all included in the power layer part of the system. The changes applied to the power layer will also affect the customer participation in an active way.

3) Communication Layer: It represents the heart of the system by providing interconnections between all of the systems and devices. The telecommunication technology is used at the communication layer to enable the data digitization, intelligent self-awareness, and increased reliability. Nowadays, existing power grids are affected by severe drawbacks, such as: 1) fragmented architectures; 2) a lack of adequate bandwidth for achieving two-way communications; 3) a lack of inter-operability between system components; and 4) the inability to handle the increasing amount of data from smart devices.

Importantly, the SG communication infrastructure could be either public or private. To this end, a public network like the Internet may offer an alternative communication path to remotely control and monitor the power grid due to its already existing shared communication infrastructure. However, when a public network is utilized for SG applications, security and quality of service (QoS) concerns may arise. Therefore, the utilities should perform a detailed cost versus benefit analysis to evaluate the performance of public versus private networks for $\mathrm{SG}$ applications. 
SMART GRID FRAMEWORK

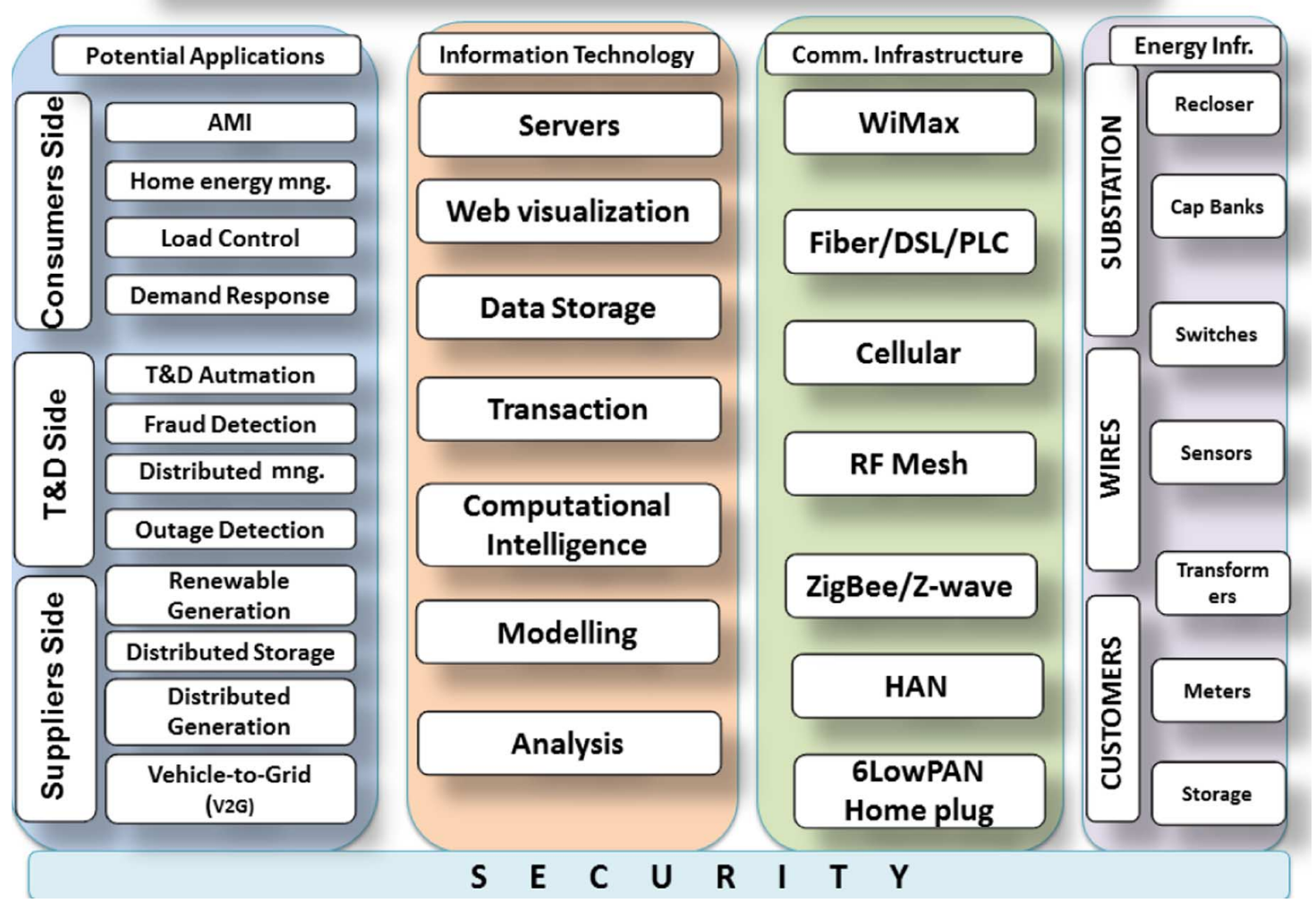

Fig. 2. SG framework depicting the potential applications, information technology, communication, and energy infrastructure of the overall system.

The communication layer consists of three transmission categories: 1) a wide-area network (WAN); 2) a field-area network (FAN); and 3) a home-area network (HAN). The three main tiers that are located between these three networks are the core backbone, back-haul distribution, and the access point [60].

The communication between back-haul aggregation points to the core backbone utility center is carried over different types of communication networks, such as star networks or fiber or wireless networks. In the following, a brief description of the transmission categories is given.

- WAN provides communication between the electric utility and substations. WAN should span all over the substations, distributed power generation and storage facilities, distribution assets, such as capacitor banks, transformers, and reclosers to be fully effective and scalable enough. It is a high-bandwidth backbone communication network that handles long-distance data transmission with advance monitoring and sensing applications. WAN provides a two-way communication network for communication, automation, and monitoring purposes of SG applications. Each SG application running on WAN has unique communication and QoS requirements. Some applications like wide-area situational awareness systems require real-time or near real-time responses; some of them, like substation automation, will require high bandwidth and fast response times; some applications, like AMI, will need considerable bandwidth and broadband data rates.

- WAN Communication: Remote communication between utility and the smart meters is essential for exchanging relevant information, such as price signals or tariff information with the customer. Cellular networks, WiMAX, and wired communications can be counted as the best candidate technologies for WAN. Importantly, the back-haul distribution system acts as an aggregation point between FAN and WAN, such as a substation, data concentrator, RF access point, or a communication tower that collects the total metering information and transfers it to the backbone communication network. Moreover, aggregation points can serve as energy-storing points for back-up power in the period of critical outages and other specific needs [13]. Fiber and microwave communication are preferred for high-bandwidth requirements and reliable communication, since this system is the aggregation point where large amounts of critical data are gathered for transmission to the back office. Licensed and unlicensed wireless technologies and fixed wire-line communication technologies can be used to transfer data from aggregation points to utilities' backhaul data centers. At the end, the communication technology will mostly depend on its cost-effectiveness and ability to provide suitable coverage.

- FAN can be described as the communication network for power distribution areas and includes distribution automation and control devices communicating over networks between individual service connections and backhaul points to the electric utilities. FAN acts as a bridge between customer premises and substations with gollectors, 


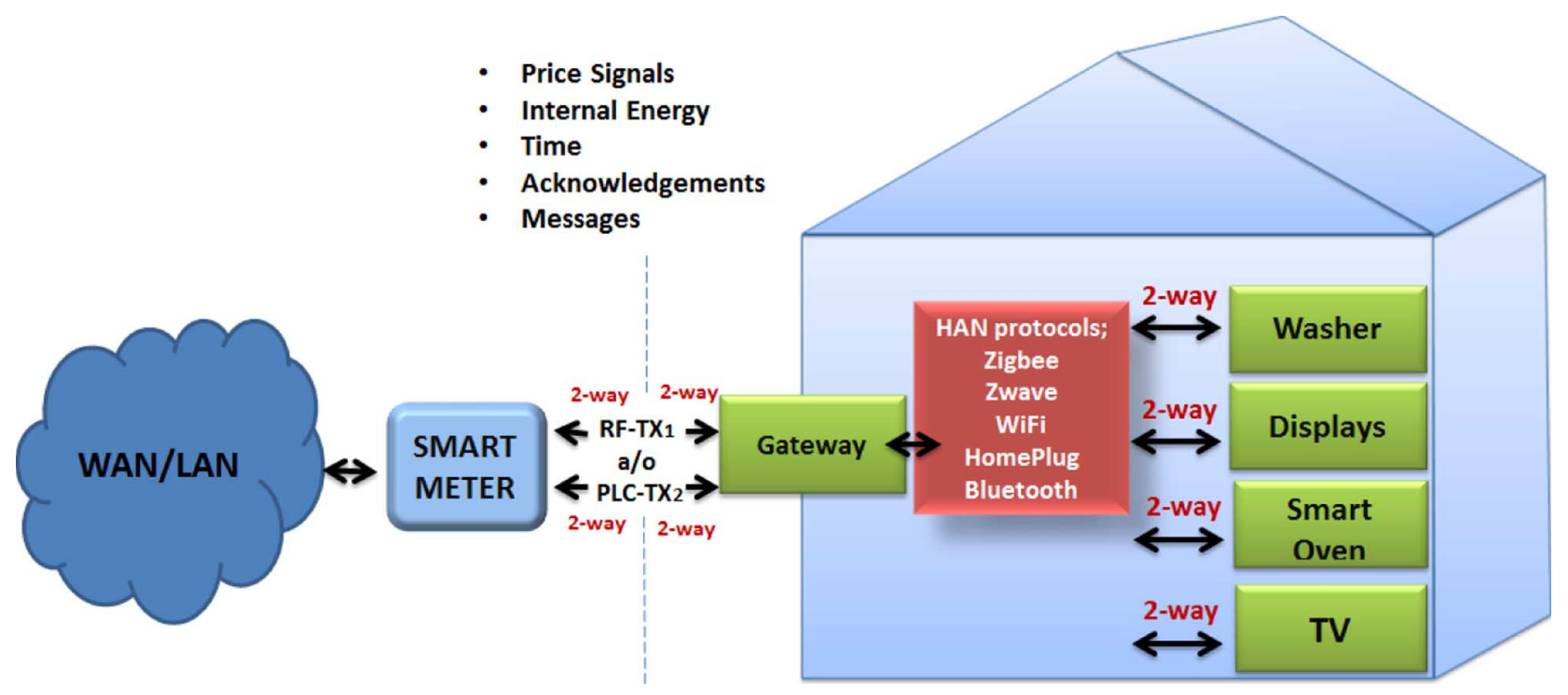

Fig. 3. SG home energy management with diverse wireless communications technology support.

access points and data concentrators. Intelligent nodes are deployed between customer premises and substations to collect and control the data from surrounding data points. These nodes are connected to a centralized gateway, which is always supported by electric utilities to transmit the collected data. Low bandwidth FAN channels are highly robust for reliable data communication. A FAN is ubiquitous and broadband wireless resource that meets the utility requirements for reliability and resilience. The coverage area includes urban-suburban and rural environments. A FAN is highly supported by advanced metering infrastructure deployments and it is rapidly expanding the range of its application areas, e.g., advanced distribution automation and integration of distributed energy resources.

- FAN Communication: The choice of communication technology varies for FAN according to different SG applications. Some electric utilities prefer fiber optic cables to have low latency and superior communication performance, others prefer WiMAX where cellular and RF mesh technologies do not have coverage over the area. Moreover, current communication trends in substation automation and distribution automation systems of FAN are towards using IEC 61850 (International Electrotechnical Commission), which provides interoperability between intelligent electronic devices and better device-to-device communication. IEC 61850 supports a wide range of applications to handle their needs. For example, the latency for mission critical data of FAN is between 3-10 ms with the integration of the IEC 61850 protocol [29].

- HAN: Smart meters will have the ability to connect to the HAN, and this will enable consumers to be aware of electricity usage costs and manage their consumption behaviors and take control of smart appliances. Home area networks support low-bandwidth communication between home electrical appliances and smart meters. The primary task of in-home applications is to inform customers about the consumption behaviors via home displays or a web interface. Hence, the bandwidth needs are between 10 and $100 \mathrm{Kbps}$ per device and there is no urgent need for low latency [60]. However, as described in Section III-C, it is expected that new functions will quickly be integrated, thus implementing intelligent load management. Low-bandwidth, slow-speed, cost-effective, and flexible connections are preferred for HAN.

- HAN Communication: The Association of Home Appliance Manufacturers (AHAM) has conducted research on the communication technologies that best meet the requirements of home-smart appliances. This research has shown that ZigBee, Wi-Fi, HomePlug, Z-wave, and M-Bus are the candidates for the HAN category. ZigBee has the ability to operate in a mesh network topology, which offers some advantages, i.e., some devices in a ZigBee mesh can remain in sleep mode when they are not active in the network, which results in energy conservation. On the other hand, $Z$-wave is an interference-free wireless standard that was specifically designed for remote control of the appliances and widely used for HANs. In Fig. 3, an illustrative architecture of a HAN is shown. In this figure, the gateways are illustrated as the output points to the HAN and some communication technologies used as HAN protocols, such as Wi-Fi, ZigBee, HomePlug, and Z-wave, are also shown. However, application-layer information models have not been fully standardized by any of the technologies above. Greenbox CustomerIQ is a system that provides customer service via an online monitoring web-site or Onzo Smart energy kit [48]. The GEO Home Energy Hub is installed at customer premises to provide a display of customers' consumption behavior [42].

\section{Applications and Communication Requirements}

The $G$ is the integration of the power grid infrastructure with an advanced communication infrastructure where different types of data can be efficiently moved with 4 varying 
degrees of security, reliability, QoS, and communication requirements. Hence, an integrated, flexible, interoperable, and secure two-way communication backbone, which meets the communication requirements of each SG component, is critical to the success of the SG. Here, some of the requirements that should be satisfied by the SG communication backbone are listed.

- Latency: Latency can be described as the delay of the data transmitted between the smart grid components. Some mission-critical applications may not tolerate any latency, such as wide-area situational awareness systems or distribution automation systems. For other applications, such as advanced metering infrastructure (AMI) or home energy management (HEMs), latency is not critical.

- Frequency Ranges: SG applications may need lower frequency ranges (below $2 \mathrm{GHz}$ ) to provide high-quality and cost-effective communication across the utility's service area. This is because lower frequency ranges can enable radio signals to overcome line-of-sight issues, e.g., foliage, rain fade, and penetration through walls [21].

- Reliability: Reliability is a metric of how reliable a communication system can perform data transfers according to the specific requirements. The communication nodes should always be reliable for the continuity of communications. Some of the SG applications, such as distributed automation, expect highly reliable data communication, and some of them can tolerate some outages in data transfer.

- Data Rate: Data rate is a closely related term specifying how fast the data is transmitted between SG components. The data-rate requirements can be different for each specific SG application. Some of the SG applications that transmit video and audio data, such as wide-area situational awareness systems, require high data-rate values to achieve a reliable and accurate data transfer. On the other hand, the communication data rates for distribution automation and AMI can be low [49]. Hence, the choice for communication technology should be determined according to specific data requirements for each application.

- Security: Security is the ability of the communication infrastructure to combat with physical and cyber security attacks to protect the critical data gathered from various smart grid components. Providing end-to-end security carries the highest priority for almost all SG applications [20]. Especially for mission critical applications, security should be provided on a communication network to prevent any vulnerabilities to the critical assets of the power grid [21].

- Throughput: The estimation of the total throughput that the SG will require for the communication systems of many applications, e.g., AMI, demand response, is 3-10 Mbps [21].

In the following, the main applications and communication requirements are summarized and analyzed in a structured way.

\section{A. Substation Automation}

Substations are key elements of the power grid network and all their devices are monitored, controlled, and protected by substation automation systems (SASs). SAS collects the data and performs actions on it allowing robust routing of power from generators to loads through the complex network of transmission lines. The communication network plays a critical role for SAS to have full control and monitoring of the real-time operating conditions and performances of substations. A highly reliable, scalable, secure, and cost-effective communication network is a prerequisite to prevent possible disruptions, e.g., power disturbances and outages. Wireless communication technologies, such as wireless mesh networks and WiMAX, are the communication technologies that can be used for SASs. Cellular technology can be used for remote monitoring of substation equipment; GPRS can be used for performing noncritical information exchange between distribution energy resources (DERs). Wireless local area network (LAN) can be used for monitoring, protection, and control of distributed energy resources, especially for remotely located small substation and DERs, where data-rate requirements and radio interference are comparatively less. The National Institute of Standards and Technology (NIST) has recognized the IEC 61850 standard for substation automation and protection applications in the SG environment, which proposes Ethernet-based communication networks to achieve interoperable SASs [59]. IEC 61850 brings an object-oriented representation of the power system by separating the functions of power substation into monitoring, control and protection [47]. Furthermore, IEC 61850 brings many advantages to substation automation systems such as the complexity of utility automated solutions and the operational and maintenance costs are reduced; the cost of copper wiring are provided with the proposition of an Ethernet-based communication network between process-level switchyard equipment [16].

- Communication Requirements of SAS: The communication requirements of substation automation are shaped by the hazardous electrical environments. The wired technologies need high protection from the problematic currents on the ground, hence wireless or fiber optic technologies are preferred mostly [60]. On the other hand, the latency requirements must be low, e.g., less than $100 \mathrm{~ms}$, to prevent communication from timing out.

\section{B. Overhead Transmission Line Monitoring}

Overhead Transmission Line Monitoring is one of the most important T\&D-side smart grid applications since transmission lines are vulnerable to icing, overheating and lighting strikes, which can adversely affect the lives of citizens. Hence, to monitor T\&D systems, wireless sensor nodes are deployed on some parts of the transmission lines and communicate with the relay node to transmit the monitored data. The relay node can be serviced by GSM/GPRS/UMTS as proposed in [8], to send the collected data via cellular communication technologies to the control center.

- Communication Requirements of Overhead Transmission Line Monitoring: The communication requirements for overhead transmission line monitoring systems depend on the network model, number of nodes and the preferred communication technology. Importantly, a large portion of energy is flowing through the transmission lines, hence, overhead transmission line monitoring systemss should 
support reliable, secure, effective and real-time communication to respond to emergency situations quickly. According to the network model that is proposed in [8], it takes $73 \mathrm{~s}$ to send information from the relay node to the sink node in a 100 node network model with hybrid communication technologies, e.g., ZigBee, GPRS, etc.

\section{Home Energy Management (HEM)}

HEMs focus on the power management on consumer side, where home appliances can be monitored and controlled to balance and optimize the power supply and consumption [3]. HEMs basically consist of smart meters, smart appliances, in-home displays, and advanced control systems. The fundamental task of the HEM system is energy efficiency [11], data measurement, and transmission. The real-time consumption data gathered from each appliance are measured and transferred to a data concentrator back to the utility. Hence, statistical analysis, intelligent advice generation, various kinds of query support, and the view of consumption data and electricity pricing can enable in-home displays to inform customers about their consumption behavior. Mesh topology can be used in HEM systems as it has many advantages due to the higher data reliability with multiple transmission paths.

- Communication Requirements of HEM: The communication needs of HEM systems on customer premises can be handled with low-power, short-distance technologies, such as ZigBee, Bluetooth, and HomePlug. There is no need for a large amount of bandwidth or communication speed, since such applications are not counted as mission critical. Verizon declares that the reasonable latency time for in-home applications should be between 2-15 s [60]. Since ZigBee is the predominant technology used in most installations and it offers flexible, low-power usage and low-cost deployment capabilities, it seems to be the best candidate for HEM systems.

\section{Advanced Metering Infrastructure (AMI)}

AMI create a two-way communication network between smart meters and utility systems and the integration of advanced sensors, smart meters, monitoring systems, computer hardware, software, and data management systems, thus enabling the collection and distribution of information between meters and utilities, allowing consumer participation in managing energy consumption [15], [32], [35], [46]. AMI does not only mean the physical deployment of smart meters, but it also is a complicated communication network and IT infrastructure, including many systems, such as a meter data management system, that handles the huge amount of data and manages the raw data to create meaningful information and messages for customers, assisting them in using energy intelligently. Hence, consumer awareness, interactive services for regulation of energy demand, avoidance of electricity-related frauds, and more timely and precise billing services are the advantages of AMI systems [4]. Fig. 6 summarizes the evolution from the early automatic meter reading (AMR), characterized by one-way communication, to the AMI, incorporating two-way communications, and to the smart grid with intelligent applications and communication infrastructure.

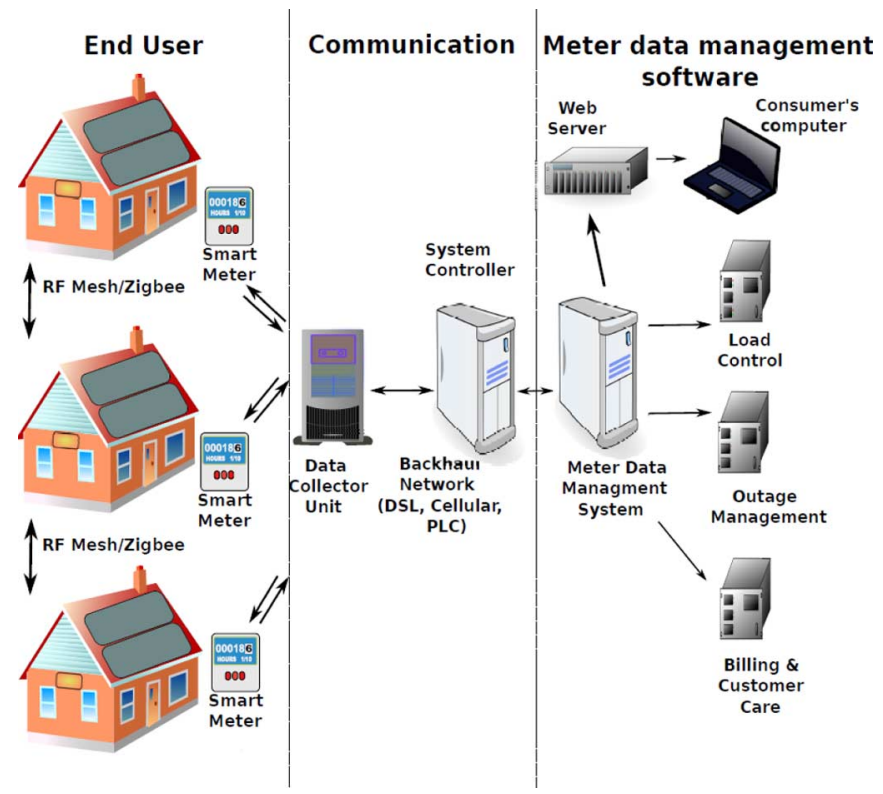

Fig. 4. Detailed architecture of an AMI.

The choice of the communication technology for AMI depends on the coverage and the number of customers per area, the availability of the Internet connection, the expected energy efficiency, scalability, the required data rate, and the expected communication delay. Fig. 4 shows some possible communication from residences to data collector units and from data collector units to meter data management systems in the AMI.

Some benefits emanating from using AMI are given here.

- Reading cost: Remote operations prevent incorrect manual readings and eliminate costly periodical readings.

- Real-time consumption information: The customers can view the real-time consumption information and real-time pricing options via home displays/dashboards and shape their consumption behaviors according to these feedbacks. This will result in shifting loads from periods of high demand to those of lower demand, hence both customers and utility companies will benefit from the optimization of energy production, transmission and distribution.

- Multi-utility service: Multiple services can be managed at the same time, such as electricity, heating, water, and gas.

- Multi-vendor service: Multiple vendors can share AMI, offering their services to customers, who can select the best market proposals, eventually changing them in real time.

- Communication requirements of AMI: Communication requirements differ according to the communication technology chosen for AMI deployments. Low-latency and higher bandwidths are essential for some AMI applications. The latency should be around 12-20 ms for real-time metering [44]. Power-line communication technology (PLC) is widely diffused, especially in urban areas, because of its use of the existing power lines. However, it may be insufficient for some real-time applications requiring bandwidths up to $100 \mathrm{Kbps}$ per device [60]. RF mesh and GPRS technology for rural AMI deployments need some coverage requirements due to the insufficient meter density. 


\section{E. Wide-Area Situational Awareness (WASA) Systems}

WASA can be defined as the integration of a set of technologies for effective power system monitoring and providing an overall, dynamic picture of the functioning of the grid [60]. Wide-area monitoring and situational awareness is one of the key functions of smart grids, since achieving reliability, security, and inter-operability among so many interconnected systems and devices is a must for utilities. Furthermore, any abnormalities such as a disturbance in power supply can result in a widespread problem that threatens the overall system reliability and security. Synchrophasors are regarded as new wide-area measurement technologies. The primary task of synchrophasors is to measure the different portions of the power system and put these measurements on the same time base, enabling a view of the whole power system at the same time and thus simplifies the comparison of different portions of the power system in real-time. Currently, Florida Power and Light and Alcatel-Lucent are supporting synchrophasor deployments.

- Communication Requirements of WASA: The latency prerequisite for real-time monitoring and control is strict. Synchrophasors is one of the wide-area measurement technologies that facilitate the integration of intermittent and renewable resources and improve system modeling and planning. The communication requirements of synchrophasors depend on the nature of data being transmitted. For example, latency requirements are very low for real-time monitoring and control. Alcatel-Lucent cites a maximum latency of $20 \mathrm{~ms}$ [60], while UTC and Avista suggest that it should be below $200 \mathrm{~ms}$ [60].

\section{F. Demand Response Management}

Demand response management (DRM) entails the control of the energy demand and loads during critical peak situations to achieve a balance between electrical energy supply and demand, thus obtaining a better utilization of the available energy and more reliable and cheaper operation of the whole power system. Customers can participate in the energy market competition by changing their energy consumption approach instead of being passively exposed to fixed prices, resulting in profits by both the companies and end-users [7]. Improving system reliability and encouraging energy efficiency are the expectations from demand response (DR) programs. Different DR programs are examined in [9], [10], and [25], such as incentive-based programs (IBP) and priced based programs (PBP). Time of use (TOU) rate, critical peak pricing (CPP), extreme day pricing (EDP), extreme day CPP (ED-CPP), and real time pricing (RTP) are some of the mechanisms that present different electricity prices for different times and conditions. Fig. 5 shows price-based and incentive-based demand response options, respectively. Time of use rate, real-time pricing and critical peak pricing are explained briefly. OpenADR is a modern automated demand response system, which is an open-source reference implementation of a distributed and client-server demand response infrastructure [31]. The integration of this system will provide effective deployment of dynamic pricing, demand response, and grid reliability.

- Communication Requirements of DRM: The communication requirements of DRM applications depend on its

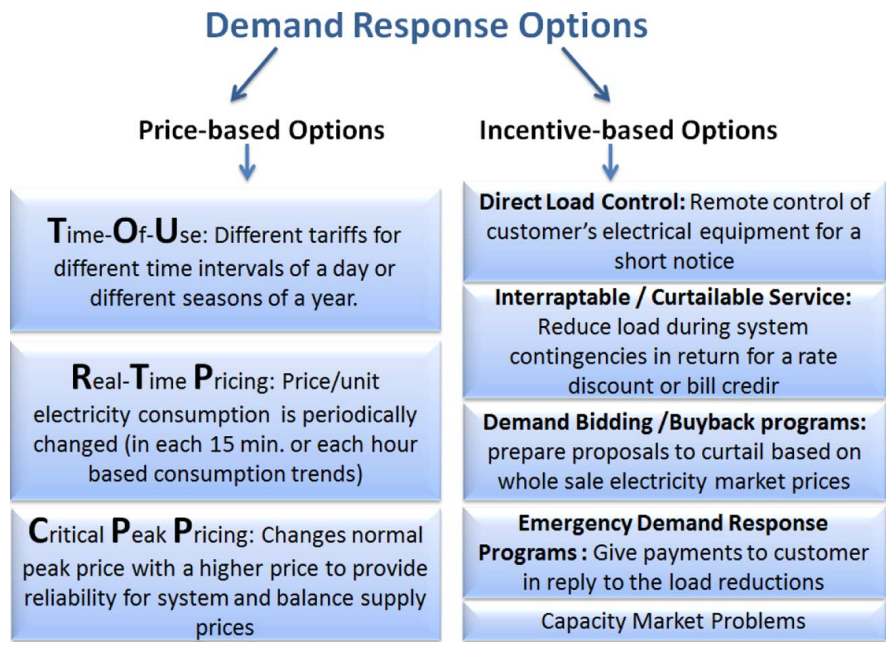

Fig. 5. Demand response options with time-of-use rates, real-time pricing, and critical peak pricing.

purpose. If it is used as a load-balancing tool, no special requirement for low latency for data transmission is needed. However, 14-100-Kbps bandwidth is required per node/ device for typical DRM programs, providing system continuity and remote turn-off of smart appliances for avoiding system overloads or simply reducing peak demands [60]. Low-speed communication can be tolerated with DRM smart devices.

\section{G. Outage Management}

Power outage is basically defined as the loss in the electricity supply for a long or short-term period. Short circuits, failures at power stations, and damage in transmission or distribution lines can be counted as reasons for power outages. Most electric utilities have been facing system outage crises. A blackout in the North-Western United States resulted in \$6 billion in losses. Hence, outage detection, management, and restoration are very critical for the continuity of reliable electricity delivery, quality of service (QoS) and customer satisfaction. In restoration processes, outage management systems (OMS) are used for prediction of outage location, service restoration, additional customer services, outage analysis and prediction, crew management, and reliability reporting. These advanced functions can be accomplished through the integration of OMS interfaces into supervisory control and data acquisition (SCADA) systems, automatic meter reading systems (AMR), utility call centers, customer information systems (CIS), and an automated mapping/facility management/geographic information (AM/FM/GIS) system. Recent discussions and activities are aimed at improving outage management processes by using smart grid technologies. AMI data integration into OMS can result in advanced customer services, improved outage management service reliability, outage notification and restoration notification. However, there have been negative business impacts on the integration of AMI and OMS in the past few years. There are many ways in which AMI can be integrated into the system and improve OMS, depending on the communication network. An outage management process is often initiated by an outage report from a customer call. However, a last-gasp or 
outage notification message from the AMI meter will be sent to the OMS sooner even if it is not reported by the customer, such as during the time when most customers are at work or sleep. The other advantage of the integration of AMI and OMS is the restoration notification functionality. Basically, it is used to improve the accuracy of reliability reports, or reduce the manpower needed to collect and analyze outages for the reports.

- Communication Requirements of Outage Management: OMS need to be integrated with other systems and require good quality of data. The communication requirements will affect all three phases of outage management, being outage realization/detection, outage discovery, and outage recovery. The main purpose of outage management is to enable utilities to respond to the power outage more quickly, hence $2000-\mathrm{ms}$ latency and 56-kbps bandwidth are the requirements of any outage management systems [60]. Furthermore, integration of advanced and highly capable wired/wireless communication networks, high-powered computers, and specialized software applications are essential for an advanced OMS.

\section{H. Distribution Automation (DA)}

An electricity distribution system acts as a bridge between the transmission system and end-user premises. Electricity is delivered through distribution systems. DA is important for utilities to provide efficiency, reliability, and quality of electric services. DA is defined as the ability to automatically and remotely monitor, control, manipulate and coordinate distribution components in real time modes. According to the US Smart Grid Market, DA has a vital role in the electricity distribution process. The emergence of DA provides much quicker fault corrections, reducing impacts and duration of outages. Area load control, load balancing, and calculation of voltage sag are some of the advance application functions that a DA system is capable of yielding. The SCADA software application system is generally used for remote manipulation to allow dispatchers to see the system failures and make remote changes easier. With the advancements introduced by smart grid, DA can be elevated a further step, known as advanced distribution automation (ADA). A more widespread communication interface and advanced integrated and coordinated protection using intelligent electronic devices, are some of the advantages of ADA. The ADA function is used in Electric Power Research Institute's (EPRI) IntelliGrid Project to provide the reliability of power system service, power quality, and power system efficiency [61].

- Communication Requirements of DA: DA is one of the mission-critical smart grid applications that is not tolerant to latency. Less than $1 \mathrm{~s}$ of latency for alarms and alert communication and $100 \mathrm{~ms}$ for messaging between points are preferred for some of the DA functions. The measured values for power system control signals should not exceed $15 \mathrm{~ms}$ [44]. In general, between 9.6- and 100-Kbps bandwidth for communications is needed for a reliable and flexible DA operation [60].

\section{Distribution Management}

Distribution networks have become too complex to be controlled and monitored manually. An advanced distribution management system (DMS) is required to provide an advanced overview of the distribution network and report abnormalities in the system. Distribution management can be defined as the ability to manage, operate and maintain the power distribution assets and provide reliable, secure and efficient power delivery. DMS has been one of the most important systems in the power industry; in other terms, it is mentioned as the actual brain of future distribution grids [5]. DMS is basically a complete ICT-based system to provide management of the overall real-time network operation. The data exchange, back-up, and coordination in DMS are always achieved via the connection to a WAN. Today DMS systems are based on existing SCADA systems. The substations are remotely monitored by SCADA systems in distribution networks and the SCADA data is not available to other system, which therefore requires manual coordination. Hence, full integration of DMS is needed to achieve intelligent communication between different assets of the distribution network. Nearly $90 \%$ of all outages originate in the distribution network, emphasizing the importance of smart distribution technologies and prompting utilities to rebuild their SCADA systems or make investment in intelligent distribution management systems. To provide interoperability and seamless data exchange between different components of the smart grid, it is essential to adopt some standards across the communication network. There are some IEC standards (IEC 62357, IEC 61970 and IEC 61968) that describe different components and their inter-relationships with a hierarchical architecture [14]. Moreover, the IEC 61850 standard aims to improve the interoperability between intelligent electronic devices (IEDs) for substation automation systems.

- Communication Requirements of DMS: DMS is a comprehensive application system that is closely connected to real-time systems and provides complete management and maintenance functions for the distribution network. Thus, highly reliable and seamless communication with real time systems, a strong integration capability and advanced interoperability between other components are the most crucial requirements for DMS. Furthermore, 9.6-100-kbps bandwidth and latency of $100 \mathrm{~ms}$ to $2 \mathrm{~s}$ is needed for reliable data communications of DMS [60].

\section{J. Asset Management}

Electric utilities have been under pressure to assure a QoS at mimimum cost for customers and regulators. Asset management has primarily been developed as a response to this problem by offering management, automation, tracking, optimization of the work order process, field crews scheduling and field assets. Assets, replacement and maintenance costs, performance of the system, risk of failure, and reliability impacts are the key drivers that can be balanced through asset management systems by the help of new technologies such as sensors, new communication infrastructures and new information and monitoring systems [27]. Most utilities use some software programs and business models to monitor and control the plant and 8 put asset 
management into practice. There are many assets that are managed through different software tools such as Asset/Work Management Systems, SCADA, and GIS. Furthermore, introducing smart grid technologies adds new assets to the system to be managed for better service at appropriate cost levels.

- Communication Requirements of Asset Management: Transmission and distribution assets are needed to be managed to improve the system reliability. Equipment condition monitoring, coordinated asset management, and dynamic adjustment of operating limits are the critical functions of an asset management system. Thus, advanced monitoring devices, seamless data traffic with other applications such as SCADA, GIS, meter data management systems and an appropriate bandwidth around $56 \mathrm{Kbps}$ [60] are required for better asset utilization.

\section{K. Meter Data Management}

Meter data management is a key requirement of the smart grid infrastructure, since the amount of metering data is growing dramatically due to the real time communication between smart meters and utilities' back office. The metering data needed to be stored, managed and further analyzed for dynamic pricing, better customer service, outage management, demand response and energy consumption management purposes. A meter data management system (MDMS) is responsible for storing and processing the metering data before making it available for other applications. Smart meters transfer the collected raw data to MDMS via a two-way communication network. MDMS acts as a database system for storing and analyzing metering data and furthermore has capabilities such as managing all kinds of meters (electric, gas, heat), transmitting data other than tariff and turn electricity on/off, etc.

- Communication Requirements of MDMS: The success of meter data management systems directly affects some critical applications such as demand response, outage management and dynamic pricing that need the information provided by MDMS. Hence, the communication requirements of MDMS are dependent on the other applications' requirements. For instance, demand response programs can be adversely affected by higher latencies in the required information. Thus, MDMS has to provide the analyzed information to DR as soon as possible. Basically, the bandwidth requirement is around $56 \mathrm{Kbps}$, and 2000-ms latency is appropriate for MDMS.

\section{Renewable Distributed Energy Resources (DER) and Storage}

DERs have an important role in the future power grid and the environment, since it is the enabler technology for lower carbon imprints, lower fuel costs, and reduced power flows on transmission lines. The renewable resources, such as solar and wind, have a non-consistent nature. Hence, they may not be available or meet the expected output levels all of the time. In this regard, energy storage systems can provide the energy during periods of reduced production. The integration of energy storage system to DERs will increase the advantages of DERs and provide a consistent, controllable, fast-acting power grid with increased reliability and power delivery capacity.
- Communication Requirements of DERs: The unpredictable nature of renewable energy resources requires fast-response, effective, and advanced communication technologies for reaching instantaneous information on different electricity generation points and advanced weather forecasting. Based on studies in [60], the bandwidth requirement is around 9.6 to $56 \mathrm{Kbps}$, and latency requirement is between $300 \mathrm{~ms}$ to $2 \mathrm{~s}$, while reliability requirement is between $99 \%$ and $99.99 \%$.

\section{Vehicle to Grid (V2G)}

In electric vehicles, the ac power (usually from 10 to $200 \mathrm{~kW}$ ) needed for traction is supplied by a group of batteries or fuel cells. The same group, when fully charged and connected to the grid can reverse its power flow routing the stored energy from the car to the power grid, thus realizing the so called "vehicle to grid" or V2G operation. Hence, EVs act as distributed resources in that the power previously absorbed from the grid or produced by the kinetic energy during motion can be sent back to the utility, which provide a smooth load curve and improve back-up capacity and reliability of the power system. One of the important roles of $\mathrm{V} 2 \mathrm{G}$ is the ability to support renewable energy. Penetration and the intermittency of renewable energy can be problematic if the fluctuating supply cannot be matched to the already fluctuating load with additional resources. In addition, V2G can provide back-up and storage for renewable energy generation.

- Communication Requirements of V2G: The communication needs of V2G should be considered for both fleet vehicles and dispersed vehicles. The communication needs of a fleet parked in one location are simple [19]. A short-range, lower cost wireless communication techniques, such as ZigBee or Bluetooth, can be used for each parking space. Long-distance communication are needed for dispersed vehicles for electronic identification of the electric utility meter that the vehicle is plugged into, billing systems and capacity identification. Hence, cellular communication technologies and land-line communication can be the best for these purposes. In case of the creation of a significant new load from EVs, transmission enhancements are required to be analyzed in the light of larger scale system planning or regional transmission planning. The communication needs are 5-10 kbps and the data latency is a maximum of $2 \mathrm{~s}$ [60].

\section{N. Electrical Vehicles (EVS) Charging}

Electrical vehicles might be one of the key solutions to the rising energy costs, increase in oil prices, and global warming issues. The energy storage seems the key technology for the realization of EVs technology [37]. To make this technology practical and real, more and more charging stations should be built. One of the challenges is also the charging time of EVs. There are some studies towards this issue. For example, the SAE J2293, SAE J2836, SAE J2847 standards have been developed for energy transfer and communication purposes between EVs and the power grid. One of the proposed methods to reduce the charging time is increasing the charging voltage and current. However, this may cause an increase in chargers' capacity, safety, size, 
cost, which can limit the ultrafast high-capacity charging. Local energy storage can be a solution for this issue, which will reduce the investments and increase the efficiency of the electrical system.

- Communication Requirements of EVs: The communication infrastructure should provide reliability, acceptable response times, and appropriate throughput. In this regard, power-line communications, GSM, GPRS, and 3G wireless WAN technologies may provide alternative solutions for EV charging applications. The estimated latency requirement is between $2 \mathrm{~s}$ to $5 \mathrm{~min}$ and the bandwidth requirement for both load balancing and billing purposes will be between 9.6-56 Kbps [60].

\section{SG Applications and Services Roadmap}

The electricity delivery systems of most countries were built almost 100 years ago, where electricity travels hundreds of thousands of kilometers from central power plants to consumers with major energy losses. The structure of the current power grid is not well suited to the distributed nature of renewable solar and wind resources, and it is the major source of $\mathrm{CO}_{2}$ emissions and does not have the capacity to meet the future energy demand. Hence, the SG has become one of the most important items on the agenda of many governments and utilities, since it is the key to increasing the recognition of the current problems, reduce the emissions of greenhouse gases, and forecast and meet the electricity demand.

As depicted in Fig. 6, there is an increasing trend from one-way communications and traditional AMR systems to smart grid technology with advances of AMI. Intelligent appliances, applications, agents, and customer portals integrate the SG system with the help of advance management, distribution automation, smart sensors, and demand response systems. Hence, in many countries, SG roadmaps have been developed to draw a global path with recommendations and action plans for further technology and policy developments. Here are some of the activities that should be focused on by the governments, regulators, utility companies, and technology firms to make meaningful progress toward the future grid development.

\section{A. Future Transmission and Distribution (T\&D) Systems}

During the Tamp;D process, a considerable amount of generated electricity, $6 \%$ to $8 \%$, is lost due to the resistance of the wires and equipment that the electricity passes through. With the SG, transmission and distribution infrastructure will be updated, new technologies will be integrated into the system to obtain better performance, and flexible ac transmission systems (FACTS) can be used to maximize the power transfer capability. High-voltage dc (HVDC) technologies can be used for the integration of renewable energy resources near the urban areas with less T\&D system losses. Dynamic line rating (DLR) can be used to identify the carrying capabilities of network parts to prevent any overloading problems, moreover, high-temperature superconductors (HTS) can be used to decrease the transmission losses [57].

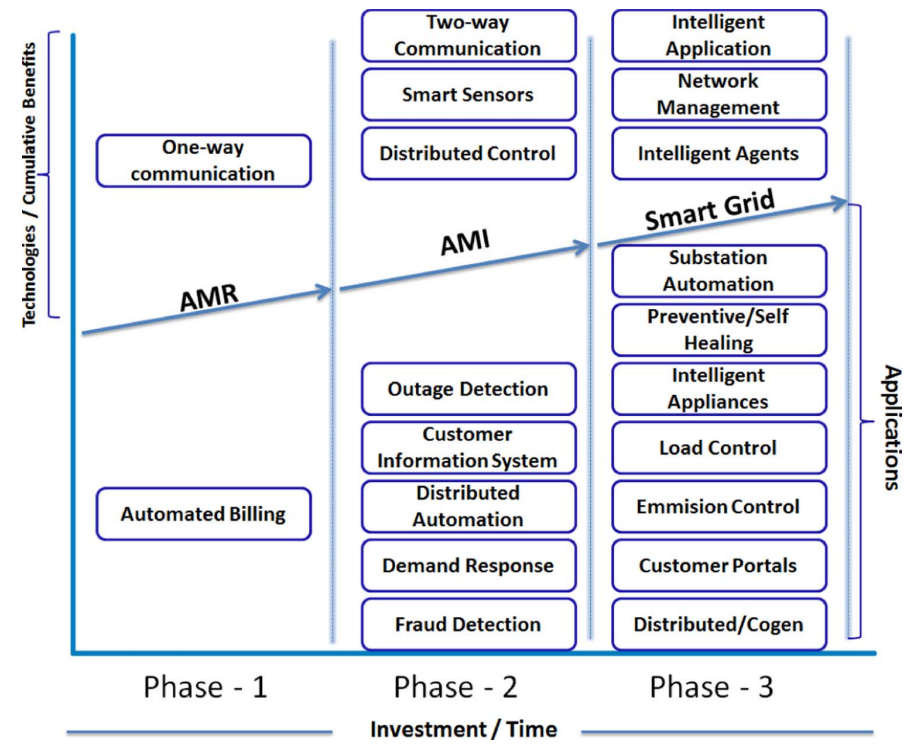

Fig. 6. SG applications road map.

\section{B. Renewable Resources}

There will be an increase in the integration of distributed solar and wind power generation plants to the power grid system, which will not cause any additional greenhouse gas emissions. There will be a greater deployment of plug-in hybrid electric vehicles (PHEVs) to avoid emissions from conventional engines of the transport sector, and the integration of storage units, weather reports, real-time output monitoring, and grid-load balancing to the system to prevent the shortages when anything may threaten the energy generation process, e.g., the wind stops blowing. With these investments, it is estimated that there will be an annual reduction in $\mathrm{CO}_{2}$ emissions that is equivalent to 60 to 211 million metric tons of $\mathrm{CO}_{2}$ in 2030 [39].

\section{Advanced Forecasting Algorithms}

The growth in electricity demand has had an accelerated increase in recent years and varies between different countries. For instance, the U.S. Energy Information Administration (EIA) stated that electricity consumption in the U.S. will increase with an annual rate of 1.07 percent from 2008 through 2030 [50]. However, the inability to forecast energy demand and to balance power supply and demand is the same problem for all of the countries. Integration of SG technologies into the existing system is promising to increase the efficiency of the supply system and meet the challenges of increasing complexity of generation loads and distributed generation resources. There will be more sophisticated DR regulations in the future, which will require two-way communications provided by AMI for more effective dynamic pricing, active customer participation and smooth integration of new technologies, e.g., HEV, EV, and PHEVs.

\section{International Collaborations}

In the revolution process of an $\mathrm{SG}$, a set of well-established, interoperable standards should be developed with the collaboration of different industrial and government organizatipn groups. 
TABLE I

REQUiREMENTS OF SG APPLICATIONS [44], [60]

\begin{tabular}{|c|c|c|c|c|}
\hline Application & Security & Bandwidth & Reliability & Latency \\
\hline Substation Automation & High & $9.6-56 \mathrm{kbps}$ & $\begin{array}{l}99.0- \\
99.99 \%\end{array}$ & $15-200 \mathrm{~ms}$ \\
\hline $\begin{array}{l}\text { Overhead Transmission Line Moni- } \\
\text { toring }\end{array}$ & High & 9.6-56kbps & $\begin{array}{l}99.0- \\
99.99 \%\end{array}$ & $15-200 \mathrm{~ms}$ \\
\hline HEM & High & $9.6-56 \mathrm{kbps}$ & $\begin{array}{l}99.0- \\
99.99 \%\end{array}$ & $\begin{array}{l}300-2000 \\
\mathrm{~ms}\end{array}$ \\
\hline AMI & High & $\begin{array}{l}\text { 10-100kbps } \\
\text { per node, } \\
500 \mathrm{kbps} \text { for } \\
\text { backhaul }\end{array}$ & $\begin{array}{l}99.0- \\
99.99 \%\end{array}$ & $2000 \mathrm{~ms}$ \\
\hline $\begin{array}{l}\text { Wide-Area Situational Awareness } \\
\text { Systems (WASA) }\end{array}$ & High & $\begin{array}{l}600- \\
1500 \mathrm{Kbps}\end{array}$ & $\begin{array}{l}99.0- \\
99.99 \%\end{array}$ & $15-200 \mathrm{~ms}$ \\
\hline Demand Response Management & High & $\begin{array}{l}14-100 \mathrm{kbps} \\
\text { per node }\end{array}$ & $99.0 \%$ & $\begin{array}{l}500 \quad \mathrm{~ms}- \\
\text { several } \\
\text { minutes }\end{array}$ \\
\hline Outage Management & High & $56 \mathrm{kbps}$ & $99.0 \%$ & $2000 \mathrm{~ms}$ \\
\hline Distribution Automation (DA) & High & 9.6-56kbps & $\begin{array}{l}99.0- \\
99.99 \%\end{array}$ & $20-200 \mathrm{~ms}$ \\
\hline Distribution Management & High & 9.6-100kbps & $\begin{array}{l}99.0- \\
99.99 \%\end{array}$ & $\begin{array}{ll}100 & \mathrm{~ms}-2 \\
\mathrm{sec} & \end{array}$ \\
\hline Asset Management & High & $56 \mathrm{kbps}$ & $99.0 \%$ & $2000 \mathrm{~ms}$ \\
\hline Meter Data Management & High & $56 \mathrm{kbps}$ & $99.0 \%$ & $2000 \mathrm{~ms}$ \\
\hline $\begin{array}{l}\text { Distributed Energy Resources and } \\
\text { Storage }\end{array}$ & High & $9.6-56 \mathrm{kbps}$ & $\begin{array}{l}99.0- \\
99.99 \%\end{array}$ & $\begin{array}{ll}300 & \mathrm{~ms}-2 \\
\mathrm{sec}\end{array}$ \\
\hline Vehicle to Grid (V2G) & High & $9.6-56 \mathrm{kbps}$ & $\begin{array}{l}99.0- \\
99.99 \%\end{array}$ & $2 \mathrm{sc}-5 \mathrm{~min}$ \\
\hline Electrical Vehicles (EVs) Charging & High & $9.6-56 \mathrm{kbps}$ & $\begin{array}{l}99.0- \\
99.99 \%\end{array}$ & $2 \mathrm{sc}-5 \mathrm{~min}$ \\
\hline
\end{tabular}

In the following, we summarize some of the smart grid standardization studies.

- Institute of Electrical and Electronics Engineers (IEEE): The IEEE is one of the world's largest professional associations for the advancement of the technology that focuses on SG interoperability standardization [55]. IEEE P2030 is the first IEEE standard providing a roadmap and guidelines for better understanding and defining smart grid interoperability [56]. Hence, IEEE P2030 has defined the SG interoperability reference model (SGIRM) to expand the current knowledge base, characteristics, and principles for SG interoperability and power grid architectural designs and operations to provide more reliable and flexible power system [1]. In general, IEEE P2030 focuses on three integrated architectural perspectives, e.g., power systems, communication technology, and information technology [56]. There exist two additional complementary standards based on the IEEE P2030 standard. IEEE P2030.1 provides guidelines on the knowledge base addressing terminology, methods, equipment and planning requirements for transportation electric-sourced, road-based personal and mass transportation applications, which can be used by utilities, manufacturers, transportation providers, infrastructure developers, and end users of electric-sourced vehicles; IEEE Standard P2030.2 focuses on discrete and hybrid energy storage systems integrated with the electric power infrastructure [1].

- International Electrotechnical Commission (IEC): IEC is the international electrical standard development organization focusing on the general requirements of smart grid architectures and smart grid efforts in the electrical industry with the creation of the IEC Smart Grid Strategic
Group in 2008 [58]. The IEC Smart Grid Strategic Group has described and identified over 100 IEC standards and examines 44 recommendations, 12 application areas, and six general topics [51]. IEC 61970 and IEC 61968 are the reference model standards to carry out the information, diverse legacy devices, and applications integration in the distribution grid and to accomplish successful SG deployment [36], [38]. Another important standard is IEC 61850, which is an electrical substation automation standard and contains data modeling, fast transfer of events, reporting schemes and data storage [43]. On the other hand, the IEC 62351 standard covers the security issues related to power system management and associated information exchange [43].

- American National Standards Institute (ANSI): ANSI is the coordinating institute of the U.S. standards and conformity assessment system that promotes the international use of the U.S. standards and protects the U.S. policy and technical position in international and regional standards organizations [52].

- National Institute of Standards and Technology (NIST): NIST has been responsible for controlling the development of standardization efforts, protocols and models for providing interoperable, reliable and secure services and systems for smart grid. With this framework, NIST presents a conceptual reference model for smart grid architecture, an initial set of 75 identified SG standards, the priorities for additional standards, initial steps for cyber security of SG and SG action plans [2].

- International Council on Large Electric Systems (CIGRE): CIGRE is one of the leading, nongovernmental and nonprofit international organizations on eleqtric power 
TABLE II

SG ROAD MAP-ACTION PLANS OF DifFERENT DOMAINS [57]

\begin{tabular}{|l|l|}
\hline Domains & Responsibility towards Smart Grid Technology \\
\hline T\&D System Operators & $\begin{array}{l}\text { Develop business models, provide optimum planning for future } \\
\text { T\&D system }\end{array}$ \\
\hline $\begin{array}{l}\text { Technology\&Solution } \\
\text { Providers }\end{array}$ & $\begin{array}{l}\text { Provide technology solutions, develop standards with industry } \\
\text { and government stakeholders }\end{array}$ \\
\hline $\begin{array}{l}\text { International Governmental } \\
\text { Organisations }\end{array}$ & $\begin{array}{l}\text { Support the RD\&D of smart grid solutions, roadmap Smart } \\
\text { Grid plans }\end{array}$ \\
\hline Consumers & $\begin{array}{l}\text { Actively participate to smart grid; may generate, store, and } \\
\text { manage the use of energy }\end{array}$ \\
\hline Government and regulators & $\begin{array}{l}\text { Collaborate with sector stakeholders, provide smart grid de- } \\
\text { ployments }\end{array}$ \\
\hline
\end{tabular}

systems that focuses on the impact of new communication standards and SGs on existing and new substations, and new ICT architectures to control the bulk power systems (e.g., smart meter, SG, and intelligent grid) [54].

- International Telecommunication Union Standardization Sector (ITU-T) Smart Grid Focus Group: A focus group on smart grids has been established by ITU-T for developing recommendations, examining the potential impacts of standardization efforts and encouraging partnerships between smart grid communities and ITU-T for smart grid deployment from a telecommunication view [51].

- Japanese Industrial Standards Committee (JISC): JISC has a central role in standardization activities in Japan, consisting of many national committees and providing contributions in international standardization activities, and contributing to the development phases of measurement standards and technical infrastructure for standardization [53].

- European Standardization Mandate M441 and the Smart Meter Co-ordination Group [51]: M441 is the mandate of standards and technical documents to the organizations European Committee for Standardization (CEN), European Committee for Electrotechnical Standardization (CENELEC) and European Telecommunications Standards Institute (ETSI) for any type of smart meter's functionalities and communication issued by the European Union. The main objective is providing reliability, interoperability and security for smart metering deployments.

- Smart Grid Standardization Mandate M/490 to European Standardisation Organisations (ESOs) to support European Smart Grid deployment: The goal of M490 is to develop or update a set of standards within a common European framework, which provides the integration of a variety of communication technologies and electrical architectures, and related processes and services. Hence, the interoperability between different high-level smart grid services and functionalities will be achieved. Building, industry, appliances and home automation are not covered in M490 and it will be coordinated with the outcomes of the existing mandate M441 to provide a coherent standardization framework [26].

- State Grid Corporation of China: China is one of the largest markets for the upcoming open standards and products for the smart grid. Hence, the State Grid Corporation of China has performed an SG standardization roadmap, which include eight domains such as planning, power generation, transmission, substation equipment and communication, distribution, utilization, dispatching, ICT, 26 technical fields, and 92 series of standards [40].

- International Organization for Standardization (ISO): ISO is an international standard body that has various representatives from national organization bodies. ISO has made SG standardization efforts in building automation and control systems (ISO 16484-5) and home electronic system architecture (ISO/IEC 14543-3).

\section{Conclusion}

Smart Grid is a foundational technology that will provide considerable changes to the existing power grid, consumer lives, the quality of power delivery, and traditional energy resources. Traditional energy sources produce energy with high environmental damage, as opposed to renewable energy sources (solar, wind, waves, and biomass), which do not present this problem, but have remarkable different dynamic characteristics than traditional ones. An integration of these into the existing energy grid is necessary and involves new technologies. The information flow is an important concept to define these technologies. On the other hand, advanced technologies and applications offered by smart grid will shave the energy consumption behaviors of consumers, and hence, a considerable reduction in energy consumption will be achieved. The integration of SG technology into the existing system has been accelerated with the SG standardization efforts of different organizations, government regulations, and SG solutions of technology and solution providers as depicted in Tables I and II. A description of communication requirements, potential applications, and the $\mathrm{SG}$ roadmap has been presented in this paper as the keys to SG development.

\section{References}

[1] T. Basso, J. Hambrick, and D. DeBlasio, "Update and review of IEEE P2030 smart grid interoperability and IEEE 1547 interconnection standards," Proc. IEEE PES Innovative Smart Grid Technol. Conf., pp. 1-7, Jan. 2012.

[2] T. Basso and R. DeBlasio, "Advancing smart grid interoperability and implementing NIST's interoperability roadmap," in Proc. Grid Interop Conf., Denver, CO, Nov. 2009.

[3] F. Bouhafs, M. Mackay, and M. Merabti, "Links to the future: Communication requirements and challenges in the smart grid," IEEE Power Energy Mag., vol. 10, no. 1, pp. 24-32, Jan.-Feb. 2012.

[4] F. Benzi, N. Anglani, E. Bassi, and L. Frosini, "Electricity smart meters interfacing the households," IEEE Trans. Ind. Electron., vol. 58, no. 10, pp. 4487-4494, Oct. 2011 
[5] S. Bruno, S. Lamonaca, G. Rotondo, U. Stecchi, and M. L. Scala, "Unbalanced three-phase optimal power flow for smart grids," IEEE Trans. Ind. Electron., vol. 58, no. 10, pp. 4504-4513, Oct. 2011.

[6] V. Calderaro, C. Hadjicostis, A. Piccolo, and P. Siano, "Failure identification in smart grids based on petri net modeling," IEEE Trans. Ind. Electron., vol. 58, no. 10, pp. 4613-4623, Oct. 2011.

[7] C. Cecati, C. Citro, A. Piccolo, and P. Siano, "Smart operation of wind turbines and diesel generators according to economic criteria," IEEE Trans. Ind. Electron., vol. 58, no. 10, pp. 4514-4525, Oct. 2011.

[8] K. S. Hung, W. K. Lee, V. O. K. Li, K. S. Lui, P. W. T. Pong, K. K. Y. Wong, G. H. Yang, and J. Zhong, "On wireless sensors communication for overhead transmission line monitoring in power delivery systems," in Proc. 1st IEEE Int. Conf. Smart Grid Commun., Oct. 4-6, 2010, pp. 309-314.

[9] C. Cecati, C. Citro, A. Piccolo, and P. Siano, "Combined operation of renewable energy systems and responsive demand in a smart grid," IEEE Trans. Sustainable Energy, vol. 2, pp. 468-476, 2011.

[10] C. Cecati, H. Yu, and P. Siano, "Real time operation of smart grids via FCN networks and optimal power flow," IEEE Trans. Ind. Inf., vol. 8, no. 4, pp. 944-952, Nov. 2012

[11] D. Dietrich, D. Bruckner, G. Zucker, and P. Palensky, "Communication and computation in buildings: A short introduction and overview," IEEE Trans. Ind. Electron., vol. 57, no. 11, pp. 3577-3584, Nov. 2010.

[12] V. C. Gungor and F. C. Lambert, "A survey on communication networks for electric system automation," Comput. Networks J., vol. 50, pp. 877-897, May 2006.

[13] V. C. Gungor, B. Lu, and G. P. Hancke, "Opportunities and challenges of wireless sensor networks in smart grid," IEEE Trans. Ind. Electron., vol. 57, no. 10, pp. 3557-3564, Oct. 2010.

[14] V. C. Gungor, D. Sahin, T. Koçak, S. Ergüt, C. Buccella, C. Cecati, and G. P. Hancke, "Smart grid technologies: Communication technologies and standards," IEEE Trans. Ind. Inf., vol. 7, no. 4, pp. 529-539, Nov. 2011.

[15] V. C. Gungor, D. Sahin, T. Kocak, S. Ergut, C. Buccella, C. Cecati, and G. P. Hancke, "Smart Grid and Smart Houses: Key players and pilot projects," IEEE Ind. Electron. Mag., vol. 6, no. 4, Dec. 2012.

[16] N. Higgins, V. Vyatkin, N.-K. C. Nair, and K. Schwarz, "Distributed power system automation with IEC 61850, IEC 61499, and intelligent control," IEEE Trans. Syst., Man, Cybern. C, Applic. Rev., vol. 41, no. 1, pp. 81-92, Jan. 2011

[17] L. Hossenlopp, "Engineering perspectives on IEC 61850," IEEE Power Energy Mag., vol. 5, no. 3, pp. 45-50, May-Jun. 2007.

[18] M. G. Kanabar and T. S. Sidhu, "Performance of IEC 61850-9-2 process bus and corrective measure for digital relaying," IEEE Trans. Power Del., vol. 26, no. 2, pp. 725-735, Apr. 2011.

[19] W. Kempton and J. Tomic, "Vehicle-to-grid power implementation: From stabilizing the grid to supporting large-scale renewable energy," J. Power Sources, 2005.

[20] H. Li, L. Lai, and W. Zhang, "Communication requirement for reliable and secure state estimation and control in smart grid," IEEE Transactions on Smart Grid, vol. 2, no. 3, pp. 476-486, Sep. 2011.

[21] B. Kilbourne and K. Bender, "Spectrum for smart grid: Policy recommendations enabling current and future applications," in Proc. 1st IEEE Int. Conf. Smart Grid Commun., Oct. 4-6, 2010, pp. 578-582.

[22] M. Liserre, T. Sauter, and J. Y. Hung, "Future energy systems: Integrating renewable energy sources into the smart power grid through industrial electronics," IEEE Ind. Electron. Mag., vol. 4, no. 1, pp. 18-37, Mar. 2010.

[23] J. A. P. Lopes, Hatziargyriou, J. Mutale, P. Djapic, and N. Jenkinset, "Integrating distributed generation into electric power systems: A review of drivers, challenges and opportunities," Electric Power Syst. Res., vol. 77, no. 9, pp. 1189-1203, Jul. 2007.

[24] H. Kanchev, D. Lu, F. Colas, V. Lazarov, and B. Francois, "Energy management and operational planning of a microgrid with a PV-based active generator for smart grid applications," IEEE Trans. Ind. Electron., vol. 58, no. 10, pp. 4583-4592, Oct. 2011.

[25] I. Koutsopoulos and L. Tassiulas, "Challenges in demand load control for the smart grid," IEEE Network, vol. 25, no. 5, pp. 16-21, Sep.-Oct. 2011.

[26] Standardization Mandate to European Standardisation Organisations (ESOs) to Support European Smart Grid Deployment, Ares(2011)233514, Mar. 2011.

[27] M. Mcgranaghan, "Making connections," IEEE Power and Energy Mag., vol. 8, no. 6, pp. 16-22, Nov.-Dec. 2010.

[28] Q. Morante, N. Ranaldo, A. Vaccaro, and E. Zimeo, "Pervasive grid for large-scale power systems contingency analysis," IEEE Trans. Ind. Inf., vol. 2, no. 3, pp. 165-175, Aug. 2006.
[29] N. G. Myoung and Y. K. S. Lee, "The design of communication infrastructures for smart DAS and AMI," in Proc. Int. Conf. Inf. Commun. Techol. Convergence, Nov. 17-19, 2010, pp. 461-462.

[30] C. R. Ozansoy, A. Zayegh, and A. Kalam, "The application-view model of the international standard IEC 61850," IEEE Trans. Power Del., vol. 24, no. 3, pp. 1132-1139, Jul. 2009.

[31] P. Palensky and D. Dietrich, "Demand side management: Demand response, intelligent energy systems, and smart loads," IEEE Trans. Ind. Inf., vol. 7, no. 3, pp. 381-388, Aug. 2011.

[32] S. Paudyal, C. Canizares, and K. Bhattacharya, "Optimal operation of distribution feeders in smart grids," IEEE Trans. Ind. Electron., vol. 58, no. 10, pp. 4495-4503, Oct. 2011.

[33] B. Ramachandran, S. K. Srivastava, C. S. Edrington, and D. A. Cartes, "An intelligent auction scheme for smart grid market using a hybrid immune algorithm," IEEE Trans. Ind. Electron., vol. 58, no. 10, pp. 4603-4612, Oct. 2011.

[34] A. Y. Saber and G. K. Venayagamoorthy, "Plug-in vehicles and renewable energy sources for cost and emission reductions," IEEE Trans. Ind. Electron., vol. 58, no. 4, pp. 1229-1238, Apr. 2011.

[35] T. Sauter and M. Lobashov, "End-to-End communication architecture for smart grids," IEEE Trans. Ind. Electron., vol. 58, no. 4, pp 1218-1228, Apr. 2011.

[36] X. Shao, J. Jiang, W. Bao, J. Chen, and K. Wang, "Researches on information framework of smart distribution grid," in Proc. China Int. Conf. Electricity Distribution, Sep. 13-16, 2010, pp. 1-6.

[37] W. Su, H. R. Eichi, W. Zeng, and M.-Y. Chow, "A survey on the electrification of transportation in a smart grid environment," IEEE Trans. Ind. Inf., vol. 8, no. 1, pp. 1-10, Feb. 2012.

[38] S. Sucic, A. Martinic, and A. Kekelj, "Utilizing standarDS-based semantic services for modeling novel Smart Grid supervision and remote control frameworks," in Proc. IEEE Ind. Conf. Ind. Technol., Mar. 19-21, 2012, pp. 409-414.

[39] "Energy savings and carbon emissions reductions enabled by a Smart Grid EPRI, 2008, Technical Paper.

[40] M. Uslar, S. Rohjans, R. Bleiker, J. González, M. Specht, T. Suding, and T. Weidelt, "Survey of smart grid standardization studies and recommendations-Part 2," in Proc. Innovative Smart Grid Technol. Conf. Europe, Oct. 11-13, 2010, pp. 1-6.

[41] A. Vaccaro, G. Velotto, and A. Zobaa, "A decentralized and cooperative architecture for optimal voltage regulation in smart grids," IEEE Trans. Ind. Electron., vol. 58, no. 10, pp. 4593-4602, Oct. 2011.

[42] T. Verschueren, W. Haerick, K. Mets, C. Develder, and F. De Turck, Architectures for Smart End-User Services in the Power Grid. Antwerp, Belgium: Ghent University-IBBT, Dept. of Information Technology-IBCN, Ghent, Belgium, Thierry Pollet Alcatel-Lucent Research and innovation.

[43] Y. Wang, D. Ruan, D. Gu, J. Gao, D. Liu, J. Xu, F. Chen, F. Dai, and J. Yang, "Analysis of smart grid security standards," in Proc. IEEE Int. Conf. Comput. Sci. Autom. Eng., Jun. 10-12, 2011, vol. 4, pp. 697-701.

[44] Y. Yan, Y. Qian, H. Sharif, and D. Tipper, "A survey on smart grid communication infrastructures: Motivations, requirements and challenges," IEEE Commun. Surveys \& Tutorials, vol. PP, no. 99, pp. 1-16.

[45] Q. Yang, J. A. Barria, and T. C. Green, "Communication infrastructures for distributed control of power distribution networks," IEEE Trans. Ind. Inf., vol. 7, no. 2, pp. 316-327, May 2011.

[46] A. Zaballos, A. Vallejo, and J. M. Selga, "Heterogeneous communication architecture for the smart grid," IEEE Network, vol. 25, no. 5, pp. 30-37, Sep.-Oct. 2011.

[47] G. Zhabelova and V. Vyatkin, "Multi-agent smart grid automation architecture based on IEC 61850/61499 intelligent logical nodes," IEEE Trans. Ind. Electron., vol. 59, no. 5, pp. 2351-2362, May 2012.

[48] “Onzo Smart Energy Kit Review," 2010 [Online]. Available: http:// onzo.com/2010/08/onzo-smart-energy-kit-review/

[49] "Smart Choices for the Smart Grid Using Wireless Broadband for Power Grid Network Transformation, TECHNOLOGY WHITEPAPER [Online]. Available: http://enterprise.alcatel-lucent.com/private/images/public/si/pdf_smartChoice.pdf

[50] Annual Energy Outlook 2008 With Projections to 2030 (Revised Preliminary Reference Case). Washington, DC: EIA, U.S. Department of Energy, 2008.

[51] "Final Report of the CEN/CENELEC/ETSI Joint Working Group on Standards for Smart Grids," 2011 [Online]. Available: ftp://ftp.cen.eu/ CEN/Sectors/List/Energy/SmartGrids/SmartGridFinalReport.pdf

[52] American National Standard Protocol Specification for ANSI Type 2 Optical Port, ANSI C12.18-2006, 2006.

[53] “Japanese Industrial Standards Committee," 2011 [Online]. Available: http://www.jisc.go.jp/eng/index.html 
[54] "Official Website of International Council on Large Electric Systems," [Online]. Available: http://www.cigre.org/

[55] :IEEE Smart Grid," [Online]. Available: http://smartgrid.ieee.org/standards

[56] "IEEE P2030 Guide for Smart Grid Interoperability of Energy Technology and Information Technology Operation With the Electric Power System (EPS), End-Use Applications, and Load," [Online]. Available: http://standards.ieee.org/findstds/standard/2030-2011.html

[57] “Technology Roadmap: Smart Grids," International Energy Agency, iea [Online]. Available: www.iea.org

[58] "IEC Smart Grid Standardization Roadmap," SMB Smart Grid Strategic Group (SG3), 2010 [Online]. Available: http://www.iec.ch/ zone/smartgrid/pdf/sg3_roadmap.pdf, 1.0

[59] "Standards Identified for Inclusion in the Smart Grid Interoperability Standards Framework," Nat. Inst. Standards and Technol., Release 1.0, 2009 [Online]. Available: http://www.nist.gov/smartgrid/standards.html

[60] Communications Requirements of Smart Grid Technologies. Washington, DC: Dept. Energy, 2010.

[61] :EPRI IntelliGrid, Distribution Operations-Overview of Advanced Distribution Automation," 2011 [Online]. Available: http://www.intelligrid.info

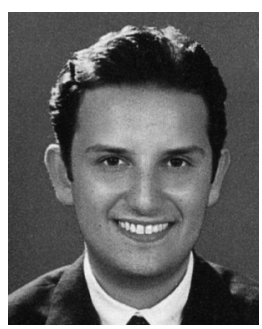

V. Cagri Gungor (M'08) received the B.S. and M.S. degrees in electrical and electronics engineering from Middle East Technical University, Ankara, Turkey, in 2001 and 2003, respectively, and the Ph.D. degree in electrical and computer engineering from the Broadband and Wireless Networking Laboratory, Georgia Institute of Technology, Atlanta, in 2007.

Currently, he is an Assistant Professor and Co-Director of the Computer Networks and Mobile Communications Lab, Department of Computer Engineering, Bahcesehir University, Istanbul, Turkey. Before joining Bahcesehir University, he was with Eaton Corporation, Innovation Center, as a Project Leader. His current research interests are in smart grid communications, next-generation wireless networks, wireless ad hoc and sensor networks, cognitive radio networks, and IP networks. He has authored several papers in refereed journals and international conference proceedings and has been serving as an editor and program committee member to numerous journals and conferences in these areas.

Dr. Gungor was the corecipient of the IEEE TRANSACTIONS ON INDUSTRIAL INFORMATICS 2012 Best Paper Award, the IEEE ISCN 2006 Best Paper Award, the European Union FP7 Marie Curie IRG Award in 2009, and the San-Tez Project Award issued by Alcatel-Lucent and the Turkish Ministry of Industry and Trade in 2010. He is also the Principal Investigator of the Smart Grid Communications R\&D project funded by Türk Telekom and the European Union.

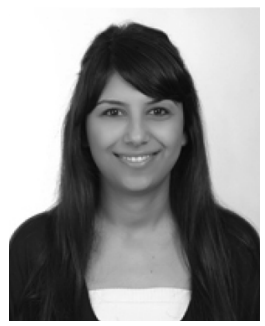

Dilan Sahin received B.S. degrees in computer engineering and in software engineering from Bahcesehir University, Istanbul, Turkey, in 2010.

Currently, she is a Research Assistant with the Computer Engineering Department, Bahcesehir University, Istanbul, Turkey. Her current research interests are in wireless sensor networks and smart grid communication and applications.

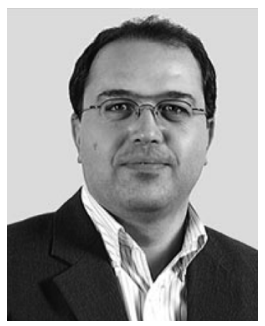

Taskin Kocak received the Ph.D. degree from Duke University, Durham, NC, in 2001.

$\mathrm{He}$ is currently a Full Professor of computer engineering with Bahcesehir University, Istanbul, Turkey. Previously, he was on the faculties of the University of Bristol, Bristol, U.K., and the University of Central Florida, Orlando. His research interests are in computer networks and communications and hardware design (computer architecture and VLSI). His research activities have produced over 100 peer-reviewed publications, including
38 journal papers, and have been supported by American, British, Japanese and Turkish funding agencies and companies, including Northrop Grumman, Toshiba Research Europe, Great Western Research, ClearSpeed Technology, KDDI, Turk Telekom, and Alcatel- Lucent. He served as an associate editor for the Computer Journal (2007-2009) and as a guest editor for a special issue of the ACM Journal on Emerging Technologies in Computing Systems.

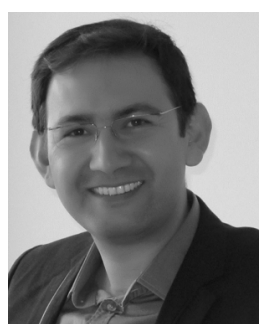

Salih Ergut received the B.S. degree from Bilkent University, Ankara, Turkey, 1998, the M.S. degree from Northeastern University, Boston, MA, in 2000, and the Ph.D. degree from the University of California at San Diego, La Jolla, in 2010, all in electrical and computer engineering.

He was with Aware, Inc., Bedford, MA, an ADSL company, in 2000. He then joined Ericsson Wireless, Inc., San Diego, CA, in 2001 and was part of an international team focusing on CDMA infrastructure for five years. He then joined Turk Telekom, Istanbul, Turkey, in 2010, where he served as the R\&D Manager responsible for university collaborations. He has been with Avea, Turkey, as sole GSM 1800 operator of Turkey, since 2011 and currently heads AveaLabs. Representing the innovative face of the company, AveaLabs consists of Innovation Center, Incubation Center, and Customer Experience Center.

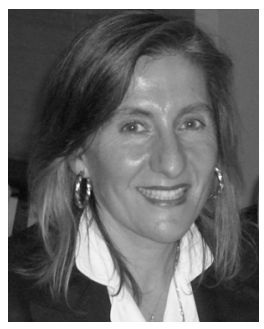

Concettina Buccella (M'92-SM'03) received the Dr. Eng. degree from the University of L'Aquila, L'Aquila, Italy, and the Ph.D. degree from the University of Rome "La Sapienza," Rome, Italy, both in electrical engineering.

From 1988 until 1989, she was with Italtel S.p.A., where she worked on the design of telecommunication equipments. Since then, she has been with the Department of Electrical and Information Engineering, University of L'Aquila, L'Aquila, Italy, where she is currently an Associate Professor and, recently, was a Cofounder of DigiPower Ltd., a spin-off dealing with industrial electronics. Her research interests include smart grids, electromagnetic compatibility, electrostatic processes, numerical methods, modeling techniques, lightning, electrostatic discharge phenomena and ultra-wideband signal interferences. In these fields, she has authored and coauthored more than 80 journal and conference papers.

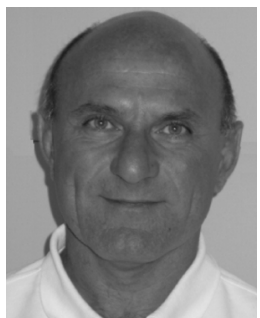

Carlo Cecati (M'90-SM'03-F'06) received the Dr.Ing. degree in electrotechnic engineering from the University of L'Aquila, L'Aquila, Italy, in 1983.

Since then, he has been with the Department of Electrical and Information Engineering, University of L'Aquila, L'Aquila, Italy, where he is currently a Full Professor of industrial electronics and drives and is a Rector's Delegate. He is the Founder and Coordinator of the Ph.D. courses on management of renewable energies and sustainable buildings at the University of L'Aquila. In 2007, he was the Founder of DigiPower Ltd., a spin-off of the University of L'Aquila, dealing with industrial electronics and renewable energies. His research and technical interests cover several aspects of industrial electronics, with emphasis on power conversion. In those fields he authored more than 100 papers published international journals and on conference proceedings. During the last 20 years, he has been involved with IEEE-IES technical activities holding several technical and administrative positions.

Dr. Cecati has been a Co-Editor-in-Chief of the IEEE TRANSACTIONS ON INDUSTRIAL ELECTRONICS since 2009. 


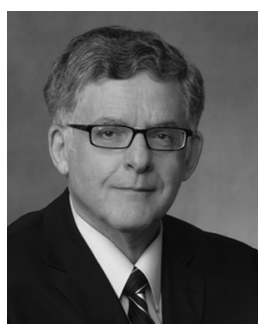

Gerhard P. Hancke (M'88-SM'00) received the B.Sc., B.Eng., and M.Eng. degrees from the University of Stellenbosch, Stellenbosch, South Africa, and the D.Eng. degree from the University of Pretoria, Pretoria, South Africa, in 1983.

He is currently with the University of Pretoria, Pretoria, South Africa, as a Professor and Chair of the Computer Engineering Program and Director of the Centre for Advanced Sensor Networks, a joint initiative between the Department of Electrical, Electronic and Computer Engineering and the Meraka Institute at the Council for Scientific and Industrial Research. His research interests are primarily in distributed sensors and actuators networks.

Prof. Hancke is a Senior AdCom member and secretary of the IEEE Industrial Electronics Society. 